University of Nebraska - Lincoln

DigitalCommons@University of Nebraska - Lincoln

Publications, Agencies and Staff of the U.S.

Department of Commerce

U.S. Department of Commerce

2012

\title{
View angle effects on MODIS snow mapping in forests
}

\author{
Qinchuan Xin \\ Boston University, xqcchina@gmail.com \\ Curtis E. Woodcock \\ Boston University, curtis@bu.edu \\ Jicheng Liu \\ I.M. System Group at NOAA/NESDIS/STAR \\ Bin Tan \\ NASA Goddard Space Flight Center \\ Rae A. Melloh \\ Cold Regions Research and Engineering Laboratory \\ See next page for additional authors
}

Follow this and additional works at: https://digitalcommons.unl.edu/usdeptcommercepub

Part of the Environmental Sciences Commons

Xin, Qinchuan; Woodcock, Curtis E.; Liu, Jicheng; Tan, Bin; Melloh, Rae A.; and Davis, Robert E., "View angle effects on MODIS snow mapping in forests" (2012). Publications, Agencies and Staff of the U.S. Department of Commerce. 360.

https://digitalcommons.unl.edu/usdeptcommercepub/360

This Article is brought to you for free and open access by the U.S. Department of Commerce at DigitalCommons@University of Nebraska - Lincoln. It has been accepted for inclusion in Publications, Agencies and Staff of the U.S. Department of Commerce by an authorized administrator of DigitalCommons@University of Nebraska - Lincoln. 
Authors

Qinchuan Xin, Curtis E. Woodcock, Jicheng Liu, Bin Tan, Rae A. Melloh, and Robert E. Davis 


\title{
View angle effects on MODIS snow mapping in forests
}

\author{
Qinchuan Xin ${ }^{\mathrm{a}, *}$, Curtis E. Woodcock ${ }^{\mathrm{a}}$, Jicheng Liu ${ }^{\mathrm{b}}$, Bin Tan ${ }^{\mathrm{c}}$, Rae A. Melloh ${ }^{\mathrm{d}}$, Robert E. Davis ${ }^{\mathrm{d}}$ \\ a Department of Geography and Environment, Boston University, Boston, Massachusetts 02215, USA \\ b I.M. System Group at NOAA/NESDIS/STAR,3206 Tower Oaks Boulevard, Suite 300, Rockville, MD 20852, USA \\ c NASA Goddard Space Flight Center Code 614.5, Greenbelt, MD, 20770, USA \\ d Engineer Research and Development Center, Cold Regions Research and Engineering Laboratory, Hanover, New Hampshire 03755, USA
}

\section{A R T I C L E I N F O}

\section{Article history}

Received 28 November 2010

Received in revised form 27 October 2011

Accepted 29 October 2011

Available online 8 December 2011

\section{Keywords:}

Remote sensing

MODIS

Snow cover

View angle effect

\begin{abstract}
A B S T R A C T
Binary snow maps and fractional snow cover data are provided routinely from MODIS (Moderate Resolution Imaging Spectroradiometer). This paper investigates how the wide observation angles of MODIS influence the current snow mapping algorithm in forested areas. Theoretical modeling results indicate that large view zenith angles (VZA) can lead to underestimation of fractional snow cover (FSC) by reducing the amount of the ground surface that is viewable through forest canopies, and by increasing uncertainties during the gridding of MODIS data. At the end of the MODIS scan line, the total modeled error can be as much as $50 \%$ for FSC. Empirical analysis of MODIS/Terra snow products in four forest sites shows high fluctuation in FSC estimates on consecutive days. In addition, the normalized difference snow index (NDSI) values, which are the primary input to the MODIS snow mapping algorithms, decrease as VZA increases at the site level. At the pixel level, NDSI values have higher variances, and are correlated with the normalized difference vegetation index (NDVI) in snow covered forests. These findings are consistent with our modeled results, and imply that consideration of view angle effects could improve MODIS snow monitoring in forested areas.
\end{abstract}

(c) 2011 Elsevier Inc. All rights reserved.

\section{Introduction}

Snow covers up to 50 million $\mathrm{km}^{2}$ (over $30 \%$ ) of the Earth's land surface seasonally (Dozier, 1989; Vikhamar \& Solberg, 2003a). The associated phase changes and unique high albedo of snow dominate local surface temperatures, impact radiative transfer and energy balance, and influence global climate. Accurate snow extent mapping is valuable for various studies, such as surface runoff and water assessment, energy balance models, and meteorological models (König et al., 2001).

Satellite sensors provide an efficient way to monitor snow as it enables mapping of large areas with high temporal frequency. Binary snow maps, which flag pixels as either snow-free or snow-covered, have been provided since 1966 when the first operational snow cover mapping was done by NOAA (Matson et al., 1986). Data from the MODIS instruments onboard Terra (launched in 1999) and Aqua (launched in 2002) are used to produce daily global snow cover products at $500 \mathrm{~m}$ resolution (Hall et al., 2002). Some studies extended their focus to estimate the fractional snow cover (FSC), primarily through spectral mixture analysis (Painter et al., 2009; Romanov et al., 2003; Rosenthal \& Dozier, 1996), a variety of models (Metsämäki et al., 2005; Vikhamar \& Solberg, 2003b), and the use of

\footnotetext{
* Corresponding author at: Department of Geography and Environment, 675 Commonwealth Avenue Room 334, Boston, Massachusetts 02215, USA. Tel.: +1 617412 7895; fax: + 16173538399 .

E-mail address: xqcchina@gmail.com (Q. Xin).
}

normalized difference snow index (NDSI) (Barton et al., 2001; Salomonson \& Appel, 2004, 2006).

Forests make remote sensing of snow more challenging especially for the MODIS sensor with wide scan angles (e.g. Hall et al., 2001; Painter et al., 2009; Salomonson \& Appel, 2004,). The importance of accurate snow monitoring in forested regions is highlighted by the fact that forests cover approximately $40 \%$ of the seasonally snowcovered areas in North America (Klein et al., 1998). The presence of trees obviously complicates monitoring of snow using remote sensing as trees obscure snow on the ground surface. This effect is exacerbated by the wide view angles of MODIS as the viewable gap fraction through forests decreases as view zenith angles increase (Liu et al., 2008). In addition, MODIS gridded products have an inherent level of noise (Tan et al., 2006) that makes it difficult to provide accurate snow cover maps.

There are other approaches for mapping the snow cover in forested areas. Vikhamar and Solberg (2003b) in Norway used a linear spectral mixture model, which includes endmembers for snow, conifer, braches of leafless deciduous trees and snow-free ground, to calculate FSC. The validation of results from MODIS data using Landsat Enhanced Thematic Mapper Plus $(\mathrm{ETM}+)$ images acquired the same days as the MODIS images showed good results when all forested and non-forested areas are included. Given the use of Landsat for validation, the MODIS results are near nadir, which is the simplest scenario. It would be interesting to test this approach at high VZA. Metsämäki et al. (2005) developed a semi-empirical model with three contributors (wet snow, forest canopy and snow-free ground) 
to estimate FSC from the reflectance observation. Their results for the Advanced Very High Resolution Radiometer (AVHRR) data are validated against in situ measurements from weather stations and snow courses located in Finland.

The purpose of this paper is to improve the understanding of MODIS snow mapping in forested areas and the MODIS snow products. Specifically, we explored the effects of the wide view angles of MODIS with both model simulation and empirical analysis of MODIS/Terra products. The modeling process consists of two major steps: i) the Geometric-Optical Radiative Transfer (GORT) model is used to estimate the viewable gap fractions (VGF) through canopies, and ii) simulation of the gridding process of MODIS data (i.e. the process of taking MODIS swath observations and assigning them to the grid cells used for the MODIS products, see Wolfe et al., 1998 for details). Empirical analysis of MODIS/Terra products is done to assess the view angle effects for four forested sites.

\section{Background}

\subsection{Snow optical properties}

The underlying idea of using optical sensors to map snow is that snow has a distinctive spectral signature. The reflectance is very high in the visible wavelengths, drops steeply in the Near-IR and remains low for longer wavelengths (Wiscombe \& Warren, 1980). Thus, NDSI, the normalized difference between green and MidInfrared reflectance, is widely used for characterizing snow (e.g. Dozier, 1989; Hall et al., 1995).

NDSI $=\frac{\text { Green }- \text { MIR }}{\text { Green }+ \text { MIR }}=\frac{\text { MODIS Band 4-MODIS Band } 6}{\text { MODIS Band } 4+\text { MODIS Band } 6}$

Snow albedo is influenced by many factors, like grain size, finite depth, and impurities (Warren, 1982). Generally, grain size will increase with age and snow reflectance will decrease in all wavelengths, but more at short wavelengths. Snow reflectance can vary from 0.9 for fresh snow to 0.5 or less for older snow in the visible wavelengths. Other factors that influence the reflectance of snow, like illumination angle, snow density, and liquid water content, can be considered equal in magnitude to the effect of changing effective grain sizes (Warren, 1982). Finite depth and impure mixtures also have considerable influence on snow reflectance in the visible wavelengths, but little effect at $0.9 \mu \mathrm{m}$ and beyond, where ice becomes a strong absorber (Wiscombe \& Warren, 1980).

\subsection{The MODIS instrument and snow mapping algorithms}

The MODIS instruments onboard the Terra and Aqua satellites are multispectral imaging radiometers with 36 spectral bands from approximately 0.4 to $14.0 \mu \mathrm{m}$ (Barnes et al., 1998). The spatial resolution of the MODIS instruments varies with spectral band, and ranges from $250 \mathrm{~m}$ to $1 \mathrm{~km}$ at nadir. MODIS provides daily, global coverage with a $2330 \mathrm{~km}$ swath width and $\mathrm{a} \pm 55^{\circ}$ across-track scan angle. The view zenith angle approaches $65^{\circ}$ at the end of a scan line.

The initial algorithm of MODIS binary snow mask used two criteria to identify snow pixels (Hall et al., 1995): NDSI greater than 0.40 , and the reflectance in MODIS Band 2 (841-876 nm, near-infrared band) greater than 0.11 . However, errors were found in forested areas where the vegetation masks snow on the ground. Therefore, Klein et al. (1998) improved the algorithm with the help of the Normalized Difference Vegetation Index (NDVI). In the new algorithm, individual pixels with NDSI values lower than 0.40 are identified as snow if NDVI values indicate that the pixels are forested. In addition, MODIS Band 4 (545-565 nm, green band) should have a minimum reflectance of 0.1 to prevent incorrect mapping of dark forests as snow.
Salomonson and Appel (2004, 2006) developed the algorithm for FSC in Version 5 MODIS snow products (MO/YD10A1). It uses a linear relationship derived via regression to retrieve FSC from NDSI. In this operational algorithm, higher NDSI values lead to higher estimates of FSC. For Terra MODIS, the function is:

Fractional Snow Cover $=-0.01+1.45 \times$ NDSI

This regression had high correlation coefficients and acceptable root mean square errors (RMSE) compared to FSC maps derived by aggregating Landsat TM binary snow maps. While this attempt to map fractional snow cover is validated with Landsat TM viewed from nadir, MODIS often collects data from much larger VZA and can lead to bias in heavily forested areas.

\subsection{View geometry effects on snow mapping in forested areas for MODIS}

View geometry may be one of the major error sources in MODIS snow mapping algorithms in forested areas. First, the gaps in forest canopies, which are essentially the detectable snow fraction in winter, will be lower at off-nadir views (Liu et al., 2008). Topography can also contribute to the view geometry effect, but is not discussed in this study. Second, toward the edges of MODIS swaths, the GIFOV (Ground-projected Instantaneous Field of View) become much larger than the grid cells to which they are assigned, with the results being that individual observations may cover several adjacent grid cells and significantly overlap each other (Wolfe et al., 1998). As a result, there are mismatches between swath observations and predefined grid cells, especially for observations at high view angles (Tan et al., 2006).

\section{Methods}

\subsection{Modeling the reflectance of forests with snow}

The scenarios for our models include green trees and snow present under the trees. With bright clear atmospheres, snow rapidly melts off of boughs and fall below the canopy. We acknowledge there are times when snow remains on the boughs and can stay there for several days or weeks. However, we have not included these cases in our modeling as in these cases it will be much easier to find areas as snow-covered.

The viewable gap fraction (VGF) at nadir equals the maximum viewable snow fractions (Liu et al., 2008):

Max Viewable Fractional Snow Cover $=$ VGF $($ Nadir $)=1-$ Forest Cover

The analytical form of the hybrid Geometric-Optical Radiative Transfer (GORT) model (Ni et al., 1999) was used to model the bidirectional reflectance of a forest stand with snow on the ground. In this model, the signal received by a sensor is a linear combination of the spectral signatures of four elements and their areal proportions (Li \& Strahler, 1986).

$\mathrm{R}=\mathrm{K}_{\mathrm{c}} \mathrm{C}+\mathrm{K}_{\mathrm{g}} \mathrm{G}+\mathrm{K}_{\mathrm{t}} \mathrm{T}+\mathrm{K}_{\mathrm{z}} \mathrm{Z}$

where $\mathrm{R}$ is the total stand reflectance, $\mathrm{K}_{\mathrm{c}}, \mathrm{K}_{\mathrm{g}}, \mathrm{K}_{\mathrm{t}}, \mathrm{K}_{\mathrm{z}}$ are the areal proportions of sunlit crown, sunlit background, shadow crown and shadow background, respectively; and C, G, T, Z are the reflectances of these four components.

This model combines the principles of geometric optics and radiative transfer theory. It treats the tree crowns as a collection of discrete ellipsoids that cast shadows on themselves and the background. The crown centers of these discrete ellipsoids are distributed randomly in space and uniformly between upper and lower height boundaries. The geometric optical method is applied to model the irradiance that 
passes through between-crown gaps directly to the ground surface, is scattered by background, and exits without further scattering by vegetation. Radiative transfer is used to calculate the probability of scattering based on path length through the canopy and provides the radiance that passes though and is scattered by plant crowns.

Required inputs of the GORT model include spectral properties of leaves and snow, canopy parameters, and illumination angles. Table 1 lists the typical values of spectral properties of leaves from the PROSPECT model (Jacquemoud et al., 1996) and snow reflectance from the model of Wiscombe and Warren (1980). These values of reflectance were chosen to simplify this simulation step and to illustrate the effects of view angles on the reflectance of canopies. Canopy parameters were from field measurements of the stands at the Fool Creek ISA and the St. Louis Creek ISA, which are both parts of the Fraser Meso-scale Study Area (MSA) in Colorado (Table 2). A more complete description of the canopy data can be found in Liu et al. (2004). Solar zenith angle was fixed at $50^{\circ}$ for exploratory purposes, but obviously varies over time.

\subsection{Simulation of the MODIS gridding process}

The term "gridding" denotes the process used to allocate image observations into an output image grid (Wolfe et al., 1998). The MODIS gridding process puts MODIS swath observations into globally pre-defined grid cells. This process can introduce the "pixel shift" effect, as the observations from any particular overpass and the grid cells are often misaligned (Tan et al., 2006).

The MODIS gridding process was simulated to quantify the effect of view geometry on snow mapping accuracy. The ground reference data are a $30 \mathrm{~m}$ fractional forest cover map (Fig. 1) obtained from the USDA Forest Service Region 5-Remote Sensing Lab. This map covers an area of $147 \times 147 \mathrm{~km}$ in the Sierra Nevada Mountains of California, and classifies the forests into nine classes with $10 \%$ cover intervals (Table 3). Pixels with the value zero could either be pixels without data or pixels with $0 \%$ forest cover, thus they were excluded in further statistical analysis.

To focus on the view angle effects, we assumed the landscape to consist of a single tree species and that all the forests have the same crown shapes as the St. Louis Creek stand. The only parameter that varies between pixels is the tree densities. Also we assumed the snow reflectance to be typical and the topography or atmospheric effects to be minor.

The method of Tan et al. (2006) was chosen to simulate the MODIS gridding process, and it took the following steps: 1) the VGF map was derived from the original $30 \mathrm{~m}$ forest cover map; 2) the scan angle, view angle, and MODIS GIFOV were calculated for each pixel with artificial satellite positions; 3 ) we put the $30 \mathrm{~m}$ VGF map under the desired view angle, and all the $30 \mathrm{~m}$ pixels falling into individual MODIS observations were weighted by the MODIS point spread function to estimate the MODIS $500 \mathrm{~m}$ swath data; and 4) the MODIS $500 \mathrm{~m}$ swath data were placed into predefined grid cells based on the observation coverage (Yang \& Wolfe, 2001) to obtain estimates of the MODIS $500 \mathrm{~m}$ gridded VGF product. The results of our estimates were validated against the reference map at $500 \mathrm{~m}$ resolution (resampled from the original $30 \mathrm{~m}$ version).

Table 1

Spectral properties of leaves and snow for the MODIS bands.

\begin{tabular}{lllll}
\hline & $\begin{array}{l}\text { B1 } \\
(645.5 \mathrm{~nm})\end{array}$ & $\begin{array}{l}\text { B2 } \\
(856.5 \mathrm{~nm})\end{array}$ & $\begin{array}{l}\text { B4 } \\
(553.6 \mathrm{~nm})\end{array}$ & $\begin{array}{l}\text { B6 } \\
(1627.1 \mathrm{~nm})\end{array}$ \\
\hline $\begin{array}{l}\text { Leaf reflectance } \\
\text { Leaf transmittance }\end{array}$ & 0.05 & 0.49 & 0.10 & 0.36 \\
$200 \mu \mathrm{m}$ Pure Snow & 0.96 & 0.42 & 0.07 & 0.35 \\
$\quad$ Reflectance & & 0.85 & 0.97 & 0.04 \\
\hline
\end{tabular}

Table 2

Canopy parameters as inputs in GORT model.

\begin{tabular}{lllllll}
\hline Stands & $\begin{array}{l}\mathrm{h} 1 \\
(\mathrm{~m})\end{array}$ & $\begin{array}{l}\mathrm{h} 2 \\
(\mathrm{~m})\end{array}$ & $\begin{array}{l}\Lambda \\
\left(\text { trees } / \mathrm{m}^{2}\right)\end{array}$ & $\begin{array}{l}\mathrm{R} \\
(\mathrm{m})\end{array}$ & $\mathrm{b} / \mathrm{R}$ & $\begin{array}{l}\text { FAVD } \\
\left(\mathrm{m}^{-1}\right)\end{array}$ \\
\hline $\begin{array}{l}\text { Dense stand in Fool Creek } \\
\text { Intermediate stand in Fool }\end{array}$ & 9.72 & 21.97 & 0.086 & 1.53 & 3.78 & 0.578 \\
$\quad$ Creek & 14.07 & 0.125 & 1.13 & 3.46 & 0.495 \\
$\quad \begin{array}{llll}\text { Sparse stand in Fool Creek } \\
\text { St. Louis Creek }\end{array}$ & 3.45 & 11.49 & 0.116 & 0.95 & 3.31 & 0.570 \\
\hline
\end{tabular}

h1: the lower boundary of crown centers; h2: the upper boundary of crown centers. $\lambda$ : crown centers density; R: horizontal crown radius; b: vertical crown radius, FAVD: foliage area volume density.

In addition, we ran the GORT model with the calculated view geometry information to add the view angle effects of forest masking, and then simulated the MODIS gridding process. This step helps to assess the total view geometry effects from both forest masking and MODIS gridding.

\subsection{Empirical analysis of MODIS/Terra products}

Four forested areas in the Northern US were picked for our empirical study of MODIS data from Jan 1st to May 19th in 2004 (140 days). Table 4 lists the precise location and meteorology information (WWW1). Since all these sites have frequent snowfall and freezing temperatures that last for the first 90 days, we assume that these areas have continuous snow cover during this time period. Fig. 2 shows the four areas at high resolution from Google Earth ${ }^{\mathrm{TM}}$, including: 1) a large flat region in Eagle River, Wisconsin; 2) a relatively flat area in Springfield, Vermont; 3) Harvard forest in Massachusetts; and 4) a small mountain area close to Lebanon, New Hampshire. All of these sites are almost homogeneous and fully covered by forests. For each location, we chose a $3 \times 3$ pixel $(1.5 \times 1.5 \mathrm{~km})$ window rather than single pixel to minimize the influence of pixel-to-pixel variability.

The FSC data were obtained from the MODIS/Terra snow cover L3 daily global product at $500 \mathrm{~m}$ resolution (MOD10A1). The MODIS/ Terra 500 m daily surface reflectance product (MOD09GA) was used to study the relationship between NDSI and sensor angles. NDSI values for each window were calculated from the averaged MODIS Band 4 (green) and Band 6 (mid-Infrared) reflectances at $500 \mathrm{~m}$ resolution. Because snow-covered forests usually have a much lower reflectance in the green band than pure snow, we set a minimum reflectance threshold of 0.01 in Band 4 to eliminate unrealistically low reflectances, which could result in very low NDSI values. MOD09GA is delivered with $1 \mathrm{~km}$ sensor and solar angle data and quality data, which were resampled to $500 \mathrm{~m}$ resolution.

The quality data provide internal cloud and cloud shadow flags, but only the internal cloud flag was used as the MODIS cloud mask is rather conservative (Stroeve et al., 2006). In addition, if there was only one clear observation in the $3 \times 3$ window, the reflectance data for that day would not be used. The results below show that some pixels could not be captured by the internal cloud algorithm, especially when they were mixed or spectrally similar to the clouds. Since even thin clouds can influence the NDSI strongly, we visually checked all the available days after applying the internal cloud mask to make sure they are free of clouds.

\section{Results}

\subsection{Modeled view angle effects of canopy masking}

VGF decreases consistently with decreasing VZA for all four sites (Fig. 3). The viewable background of all four stands at nadir drops by about $50 \%$ at the largest MODIS view zenith angle. For instance, the Dense Stand has a $60 \%$ gap at nadir but only less than $4 \%$ gap at 


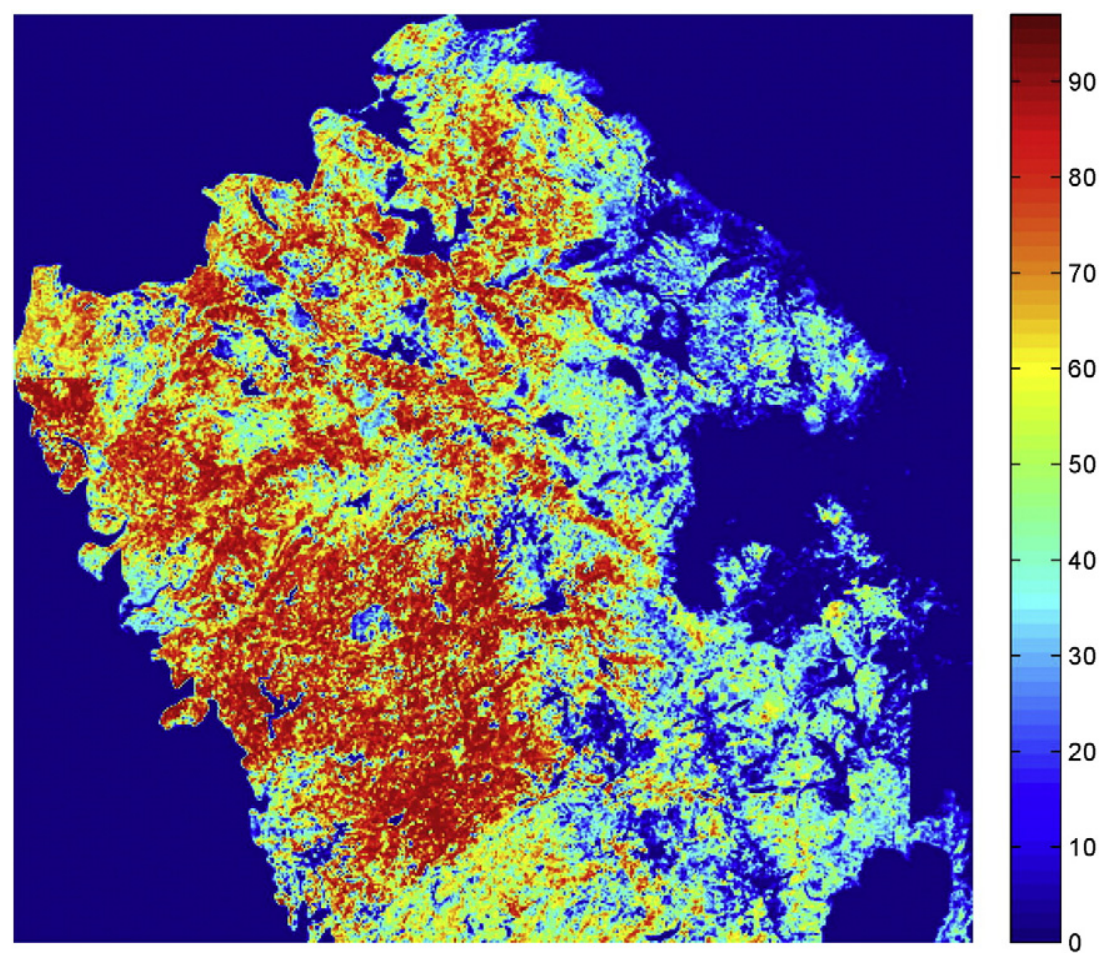

Fig. 1. The $30 \mathrm{~m}$ fractional forest cover map of the Sierra Nevada Mountains in California.

VZA of $65^{\circ}$ (nominally, MODIS has $\pm 55^{\circ}$ scan angle, which is about $\left.\pm 65^{\circ} \mathrm{VZA}\right)$.

We chose the St. Louis Creek stand as an example to show GORT modeled reflectances. Reflectance in the principal plane is influenced by the hotspot effect, where the view geometry coincides with the solar geometry. Considering large solar zenith angle in winter, MODIS sensor rarely collects data near the hotspot, so results in the cross-principal plane are closer to the real MODIS acquisitions. In Fig. 4, modeled reflectances generally decrease in the visible bands, but increase in the mid-infrared and near-infrared as view angles increase. For landscapes with only snow, mid-infrared reflectance should be much lower than green; but here we see that the trees have a significant effect: mid-infrared reflectance is similar to green wavelengths and even greater at large VZA.

The dependence of NDSI on the VZA (Fig. 5) illustrates how the view angle can influence the performance of the current MODIS snow algorithm for snow-covered forests. The NDSI and NDVI values were calculated from GORT modeled band reflectances. These values of all four stands have similar dependence on the VZA, but with different magnitudes. Although the NDSI values remain positive for the Sparse Stand, NDSI decreases rapidly with increasing VZA, while the NDVI values increase slightly. The MODIS snow mask can correctly identify these stands as snow-covered if viewed at nadir, but would have troubles at large VZA. Snow cover in the Dense Stand will be missed when the VZA is greater than $5^{\circ}$ because the NDSI values are negative. NDVI remains positive at all view angles, even for the Sparse Stand at nadir. Since the NDSI values change with VZA, the MODIS snow products may give different fractional snow cover values for observations from

Table 3

Class information of the forest cover map in Sierra Nevada, California.

\begin{tabular}{lcccccccccc}
\hline Forest cover (\%) & 0 & 10 & 20 & 30 & 40 & 50 & 60 & 70 & 80 & 90 \\
$\begin{array}{c}\text { Percentage of all } \\
\text { pixels (\%) }\end{array}$ & 48.2 & 1.2 & 2.6 & 4.9 & 7.4 & 7.6 & 6.3 & 5.3 & 5.7 & 10.6 \\
pixel & & & & & & & & & &
\end{tabular}

different days, even though the snow cover does not change significantly.

The important factors in the GORT simulation include the shape of the trees, forest and snow optical properties, and solar geometries. The ellipsoid shape was used in this study instead of a conical shape, since it has already been shown to be effective for estimating VGF though forest canopies (Liu et al., 2008). In addition, we modeled the reflectance of individual bands and NDSI against VZA with varying tree and snow optical parameters at different solar zenith angles. Spectral reflectance shows strong dependence on some of these inputs, for example, leaf transmittance, snow grain sizes and impurities, and solar zenith angles. However, the outputs of our simulations still show the strong correlations between NDSI and VZA presented here.

\subsection{The view angle effect of the MODIS gridding process}

The symmetric pattern in Fig. 6 indicates that the VZA introduces random uncertainties during the MODIS gridding processes because the GIFOV of MODIS sensor is changing with increasing VZA. This effect could result in either overestimation or underestimation of the snow cover fraction, depending on the forest cover in the areas surrounding the grid cells. VGF estimates have higher uncertainty from the MODIS gridding process at larger VZA, with RMSEs of $6.46 \%$, $8.15 \%$ and $11.1 \%$ for a VZA of $5^{\circ}, 30^{\circ}$, and $55^{\circ}$, respectively.

Table 4

Information about four forest sites.

\begin{tabular}{|c|c|c|c|}
\hline \multirow[t]{2}{*}{ Location } & \multirow[t]{2}{*}{ Coordinates } & \multicolumn{2}{|c|}{$\begin{array}{l}\text { Jan } 1 \text { st } 2004 \text { to Mar 30th } \\
2004 \text { (first } 90 \text { days) }\end{array}$} \\
\hline & & $\begin{array}{l}\text { Total snowy } \\
\text { days }\end{array}$ & $\begin{array}{l}\text { Avg max } \\
\text { temperature }\end{array}$ \\
\hline Eagle River, Wisconsin & $45^{\circ} 55^{\prime} 39^{\prime \prime} \mathrm{N} 88^{\circ} 50^{\prime} 14^{\prime \prime} \mathrm{W}$ & 61 & $-2.8^{\circ} \mathrm{C}$ \\
\hline Springfield, Vermont & $43^{\circ} 23^{\prime} 05^{\prime \prime} \mathrm{N} 72^{\circ} 32^{\prime} 18^{\prime \prime} \mathrm{W}$ & 40 & $-0.56{ }^{\circ} \mathrm{C}$ \\
\hline $\begin{array}{l}\text { Harvard forest, } \\
\text { Massachusetts }\end{array}$ & $42^{\circ} 31^{\prime} 04^{\prime \prime} \mathrm{N} 72^{\circ} 12^{\prime} 49^{\prime \prime} \mathrm{W}$ & 31 & $0.56{ }^{\circ} \mathrm{C}$ \\
\hline Lebanon, New Hampshire & $43^{\circ} 43^{\prime} 06^{\prime \prime} \mathrm{N} 72^{\circ} 08^{\prime} 42^{\prime \prime} \mathrm{W}$ & 41 & $-1.1^{\circ} \mathrm{C}$ \\
\hline
\end{tabular}




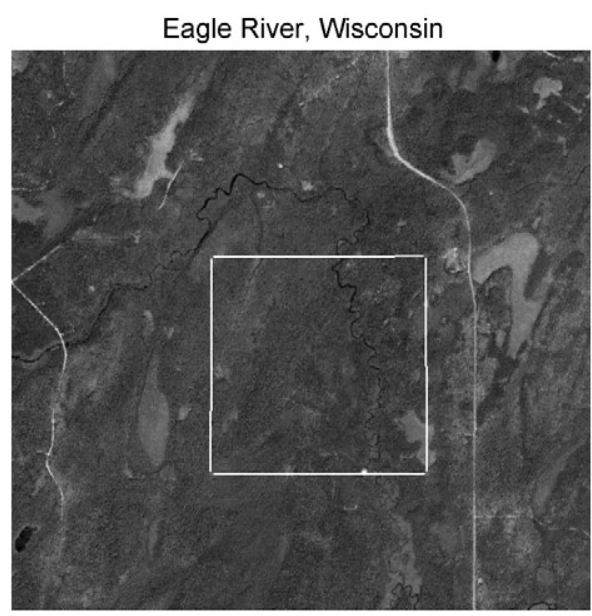

Harvard forest, Massachusetts

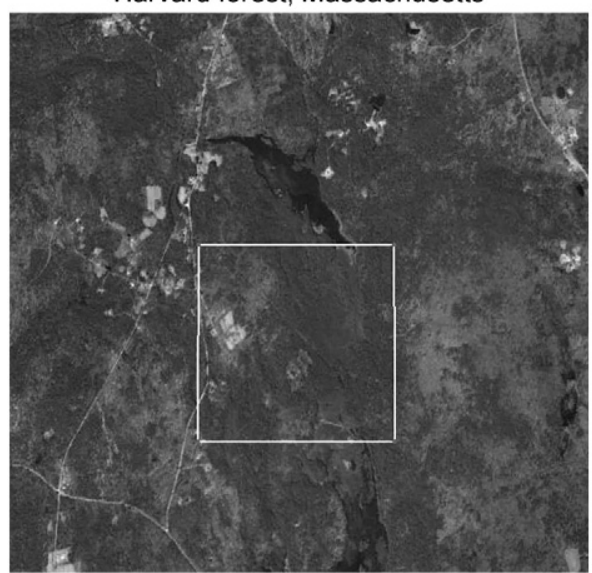

Springfield, Vermont

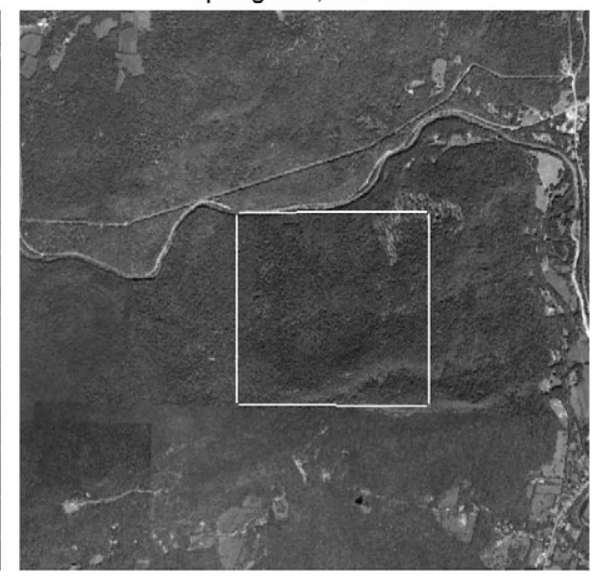

Lebanon, New Hampshire

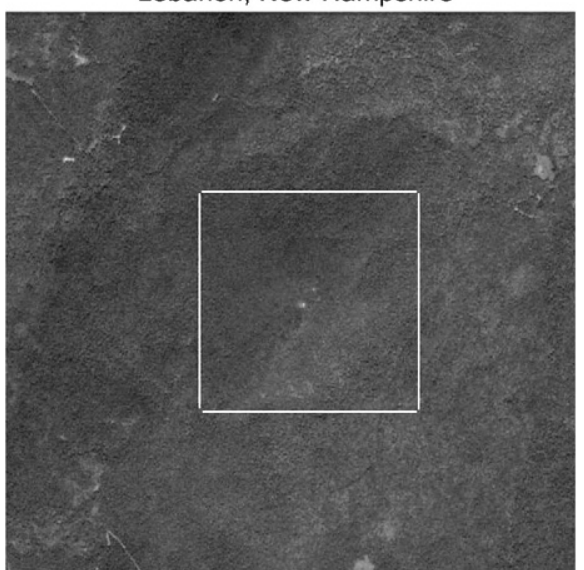

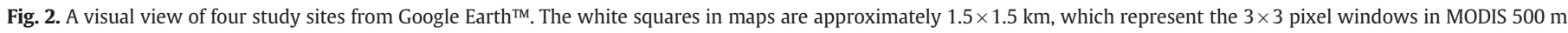
gridded products.

The effects of combing both changes in VGF and the gridding process are shown in Fig. 7. Increasing VZA can substantially reduce overall VGF and gradually shifts the pattern to underestimation. The symmetrical pattern at nadir indicates that the effects are mainly a result of the gridding process. At off-nadir view angles, the canopy masking effect dominates. In Fig. 7c, most VGF estimates are lower than $10 \%$, which is the lowest value in the original map. The RMSE values also increase with increasing VZA, and could be as high as $31 \%$ at VZA of $50^{\circ}$, or close to the end of MODIS scan lines.

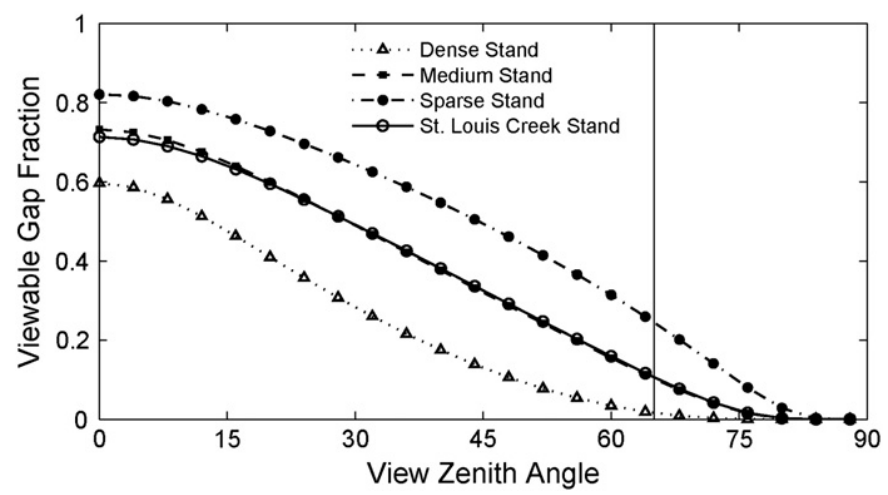

Fig. 3. Viewable gap fractions (VGF) as a function of view zenith angle (VZA) for the four stands modeled with the GORT model. The black solid line on the right represents the end of the MODIS scan line.

\subsection{Empirical analysis}

When the averaged NDSI values for the four forested sites are plotted as functions of view zenith angle, the effect of high view angles in forested landscapes is obvious (Fig. 8). Second-order polynomial curves can fit these points well. As observations move away

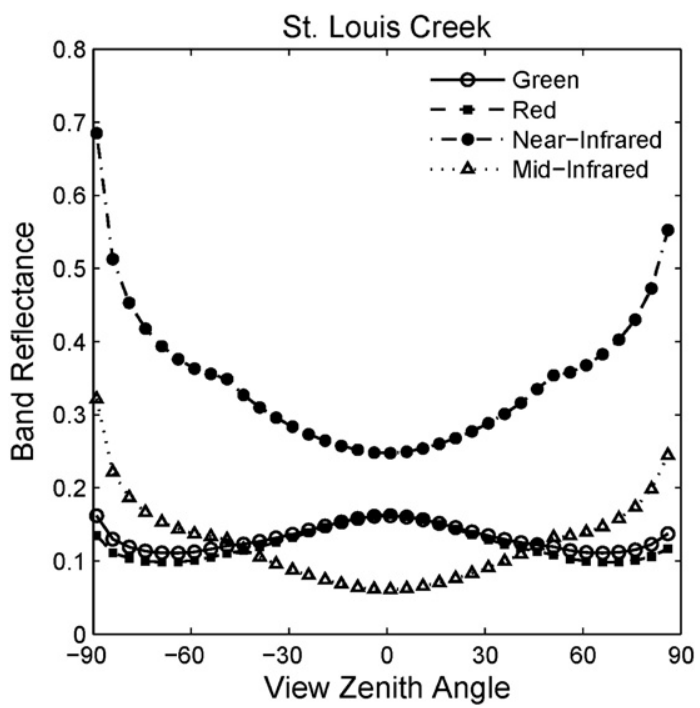

Fig. 4. GORT modeled band reflectance as a function of view zenith angle in the cross principal plane for the St. Louis Creek stand. Solar zenith angle is fixed at $50^{\circ}$. 

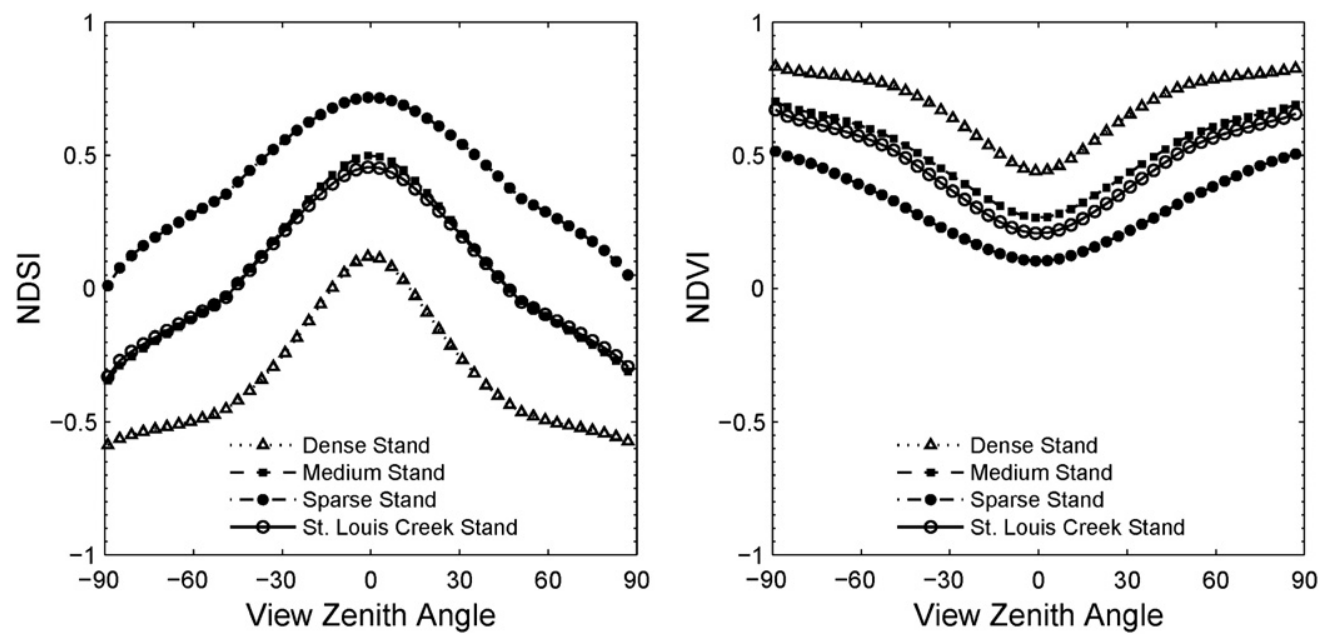

Fig. 5. GORT modeled NDSI and NDVI as a function of view zenith angle in the cross-principal plane for four different stands. Solar zenith angle is fixed at $50^{\circ}$.

from nadir, NDSI decreases at all sites. Because the presence of forest can lower the green reflectance significantly, NDSI can be negative even with snow on the ground. For example, at the Springfield site, NDSI ranges from about 0.5 at nadir to -0.3 off-nadir. After snowmelt, NDSI remains low and is independent of view angles. These findings are consistent with the GORT model results and reflect the view angle effects of canopy masking (Fig. 5). In addition, the different rates of decline may reflect canopy densities. The polynomial curves at the Eagle River, Springfield, and Lebanon sites are close to the modeled curves of the Intermediate stand, while the Harvard forest site is similar to the Dense Stand.

Application of the MODIS snow mapping algorithm needs to be done at the individual pixel level, rather than at the aggregated level shown in Fig. 8. The NDSI values of individual pixels (Fig. 9) have more variability than the averaged NDSI of the window at the same site, since observations from a single pixel usually couple with the MODIS gridding effect. This could explain why some observations are far from the fitted lines for the $3 \times 3$ window. After snowmelt, the NDSI values of both the center pixel and the $3 \times 3$ window are consistently low. The MODIS snow mask performs fine for VZA up to about $30^{\circ}$ at the Eagle River, Springfield and Lebanon sites, but is ineffective at the dense Harvard Forest site. Applying the MODIS fractional snow regressions, the FSC could range from zero to around $80 \%$ even if all these sites remained snow-covered during the snow season.

Fig. 10 shows the FSC values in the MODIS snow cover products for the four forest sites. The dramatic changes of the FSC values on consecutive days are unrealistic during the snow season. For example, the FSC decreases from over $40 \%$ to about $0 \%$ and then increases to $50 \%$ in just 7 days at the Springfield Site. The FSC estimates are always zero after snowmelt (near Day 100) and can easily be separated from the snow season. These findings cannot be explained by the snowmelt or snowfall events, but are consistent with our expectations for significant view geometry effects: MODIS has very different view angles for the same area on consecutive days, thus the fluctuating FSC estimates are results of both underestimation of canopy masking effects and uncertainties in the gridding process.

\subsection{Correlation between NDSI and NDVI}

Strong correlations are found in the GORT model results when NDSI are plotted against NDVI with varying view angles in the cross-principal plane (Fig. 11). Empirical analysis also shows that NDSI is highly correlated with NDVI in snow-covered forests (Fig. 12). Linear regressions between NDSI and NDVI are performed separately for each site with all the cloud-free data of each pixel in the $3 \times 3$ window, excluding those after snowmelt. The four sites show high R-square values of $0.72,0.80,0.80$, and 0.75 , respectively. This is another way of showing the strong view angle effects in MODIS: when viewing away from nadir, we see more trees and less snow, thus NDSI deceases while NDVI increases. This finding also implies that NDSI is probably not a good index for deriving FSC from
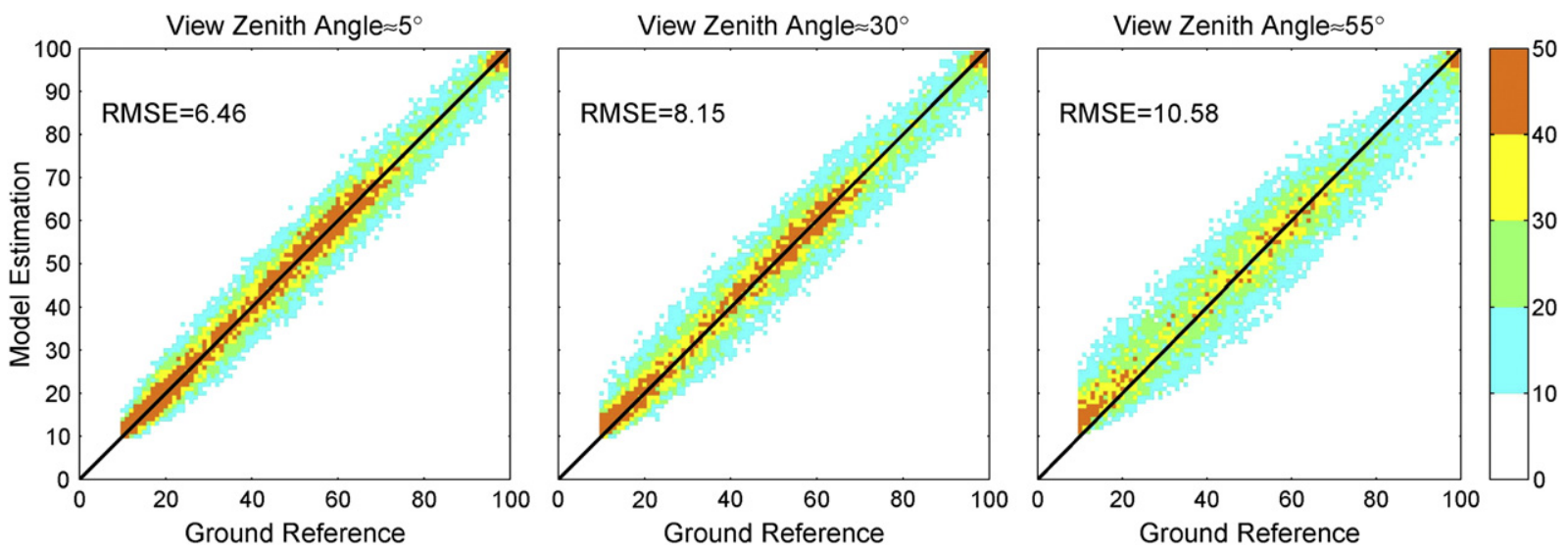

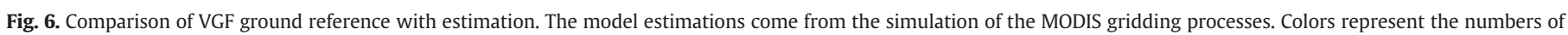
pixels. The solid line is the 1:1 line, where the estimates are equal to ground references. 

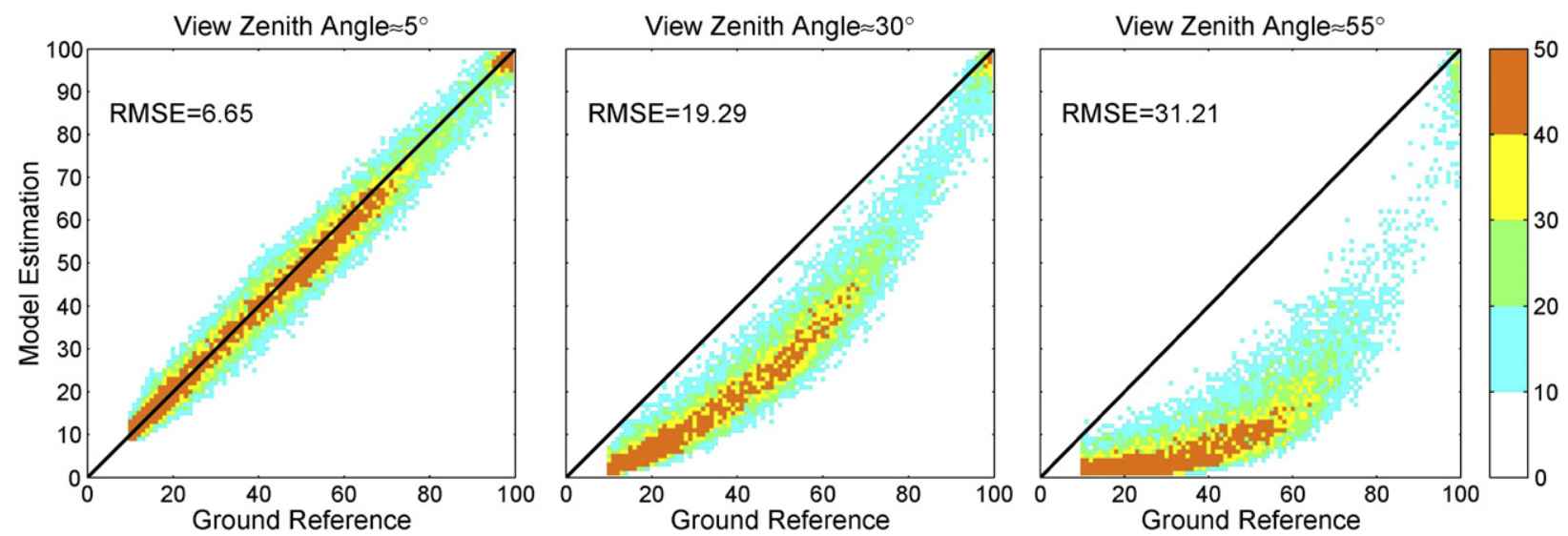

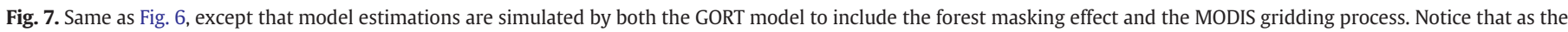
view zenith angle increase, so do the magnitudes of errors.

MODIS products for forested areas, since it is so closely related to NDVI.

The percentages of observations identified as snow-covered by the MODIS binary snow algorithm are shown in Fig. 12. The observations that fall in the triangles or to the right of the vertical line (NDSI > 0.4) in Fig. 12 will be classified as snow in the latest version of the MODIS binary mask, whereas only pixels to the right of the vertical line would have been classified as snow in the old version of the snow mask. The initial binary snow algorithm cannot effectively detect snow in forested areas. The added triangle in the NDSI-NDVI domain improves the snow mapping accuracy by recognizing that additional $28 \%, 25 \%, 4 \%$ and $32 \%$ of these stands are snow-covered. However, over $60 \%$ of the observations are still not correctly identified as snow-covered, especially those acquired at large VZA. Pixels after snowmelt are generally very low in NDSI and distinguishable from the others, although some snow-covered pixels may also exhibit very low NDSI values. While NDVI stays above zero for forested areas, NDSI is often negative even when snow is present. This implies that the usage of NDSI alone to discriminate snow is quite limited in snow-covered forests.
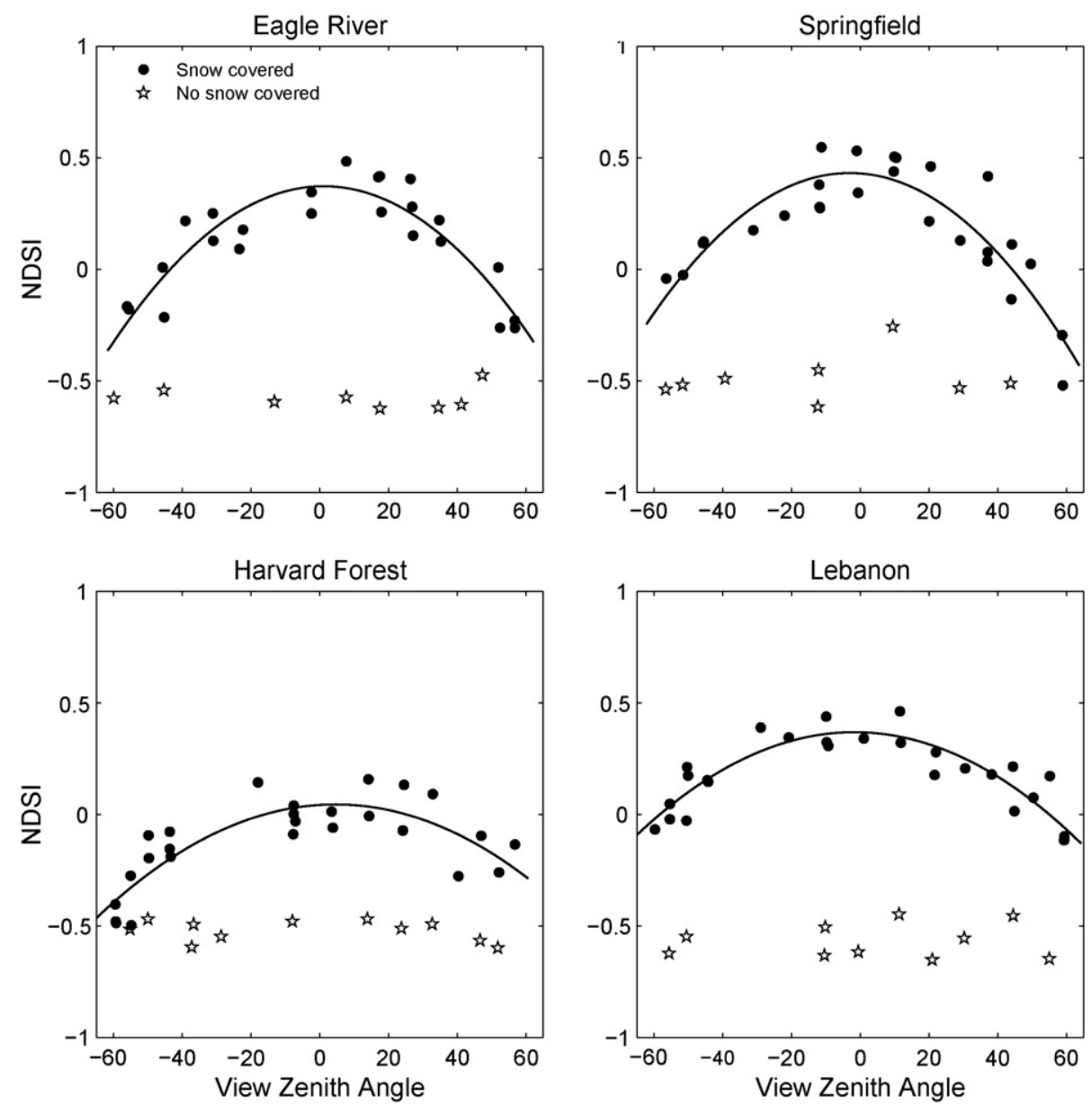

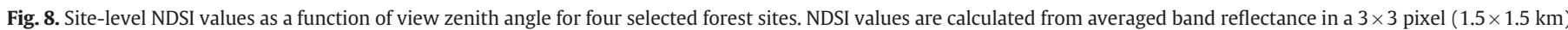
window. The solid line is a second-order polynomial curve fitting the values during the snow season. 

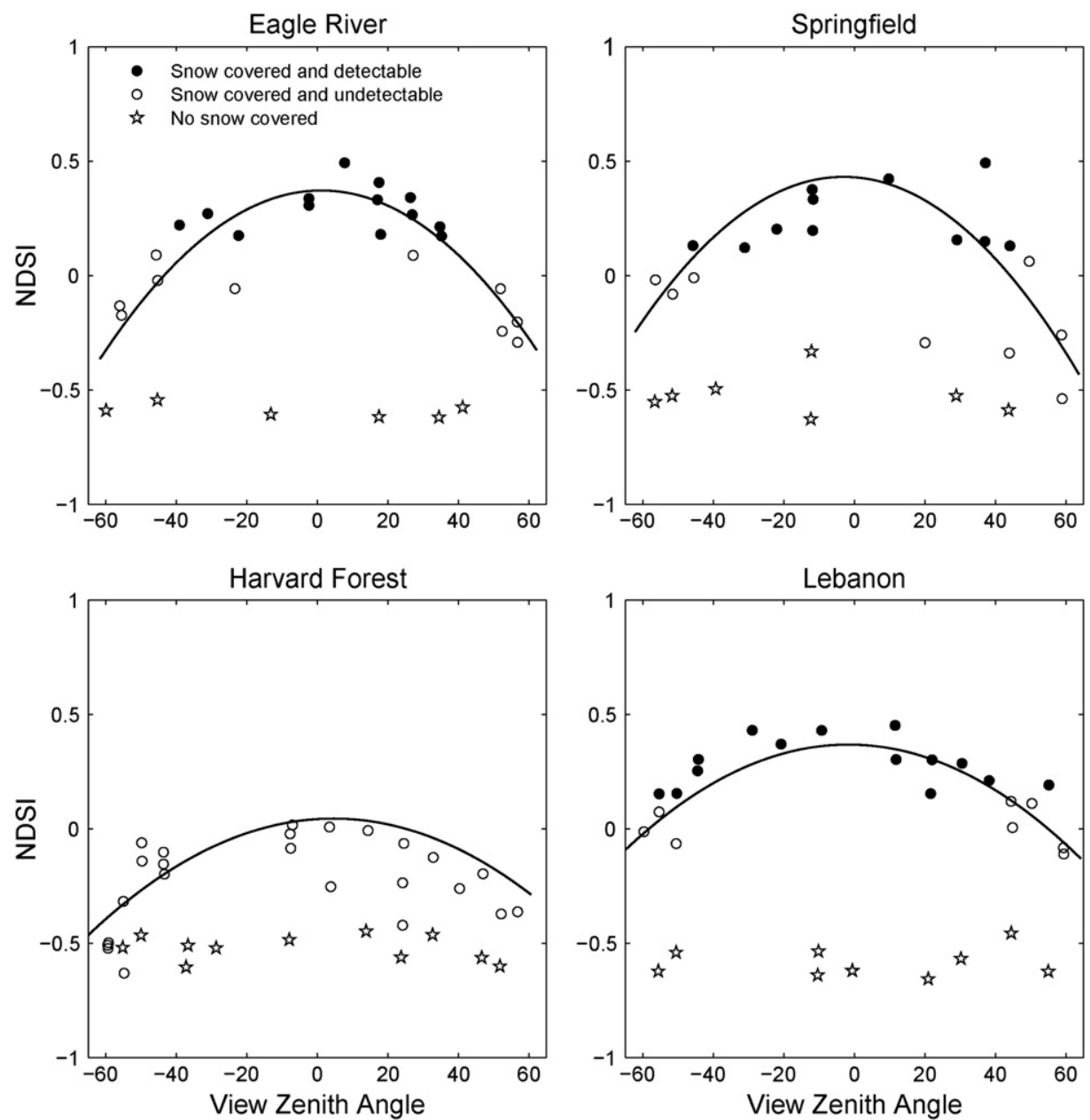

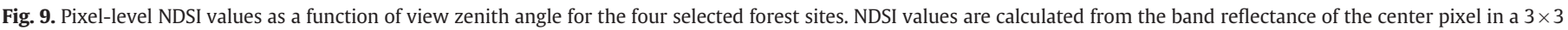

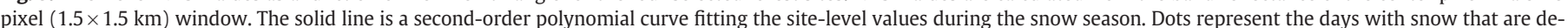

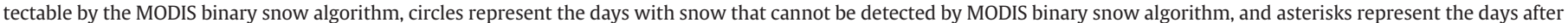
snowmelt.

\section{Discussion and conclusions}

We have demonstrated why it is difficult to monitor snow accurately in forested areas for sensors with wide view angles like MODIS. Both model outputs and empirical research show that the snow cover identification and fractional snow coverage using the MODIS algorithms vary considerably in forested areas. The variation

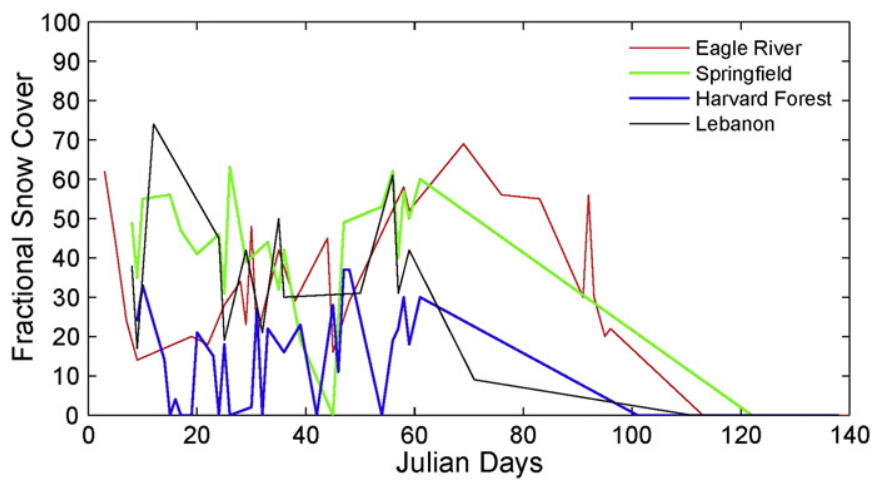

Fig. 10. Fractional snow cover from MODIS snow products (MOD10A1) at four forest sites from Jan 1st to May 19th, 2004. The FSC values of each site are from the center pixel in a $3 \times 3$ pixel $(1.5 \times 1.5 \mathrm{~km})$ window.

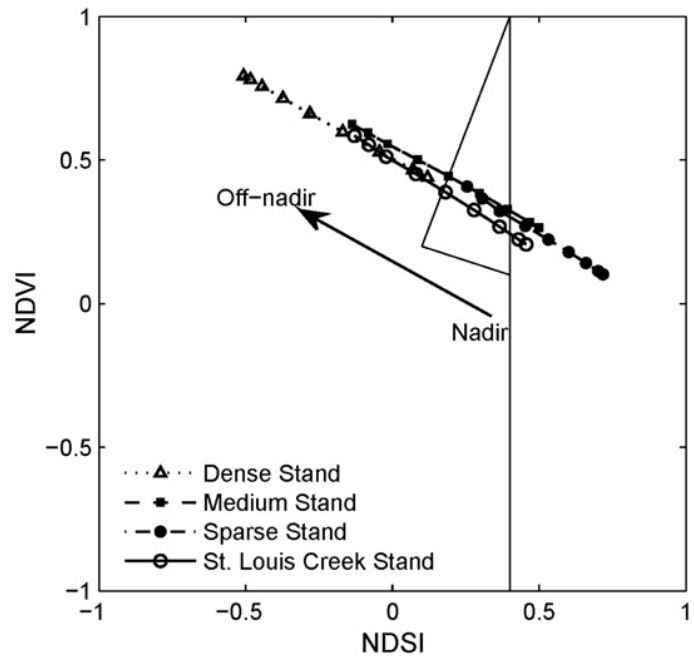

Fig. 11. GORT modeled NDVI against NDSI for the four forest stands with snow on the ground. NDVI and NDSI values are calculated from reflectances in the cross-principal plane. For each stand, nadir observations are at the end of the line at the bottom right. As view zenith angle increases, the values move to the upper left with a maximum view zenith angle of $65^{\circ}$. The MODIS snow mask flags observations as snow if they fall in the triangles or to the right of the vertical line (NDSI $>0.4$ ). 

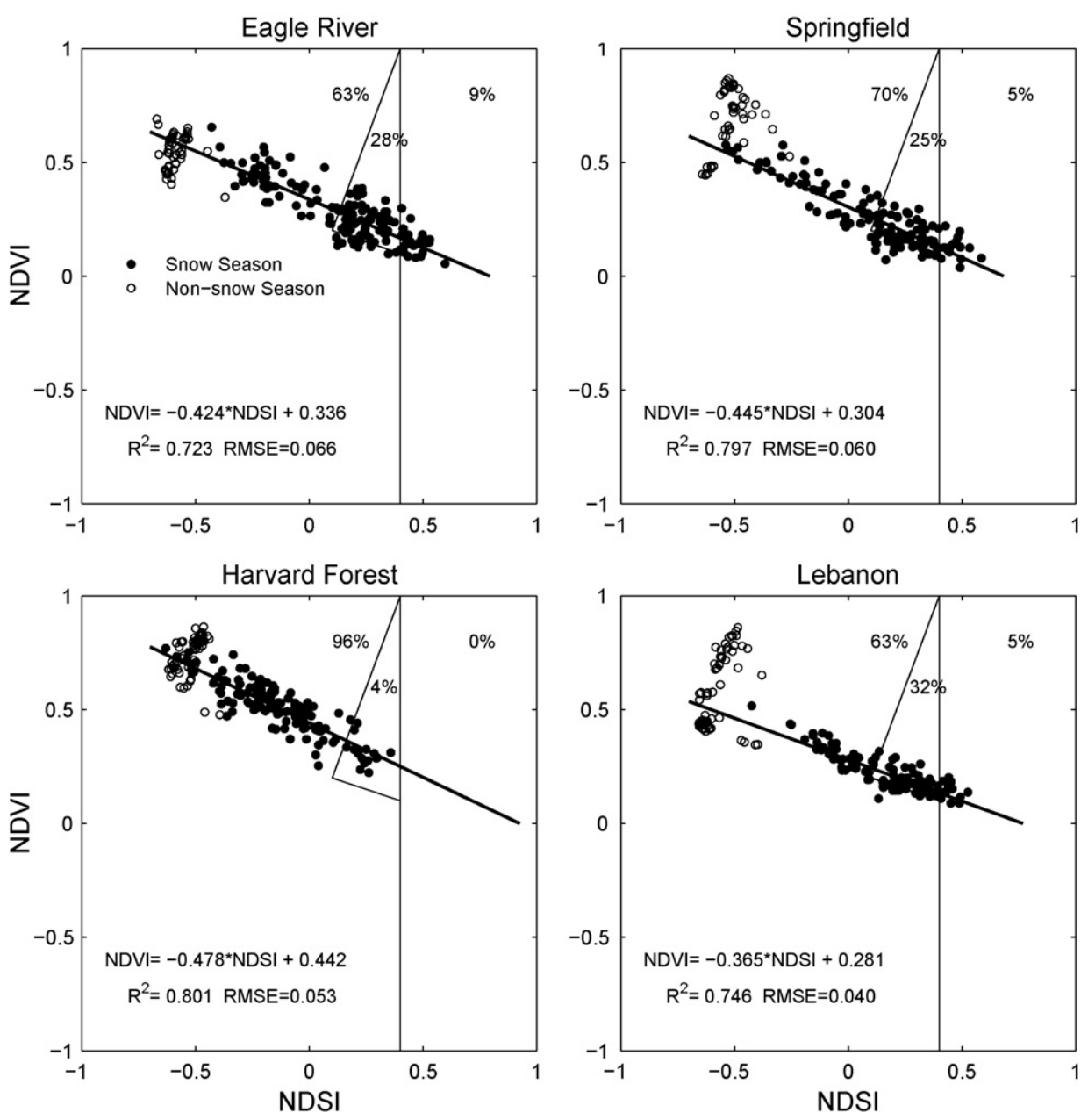

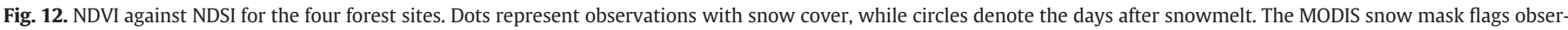

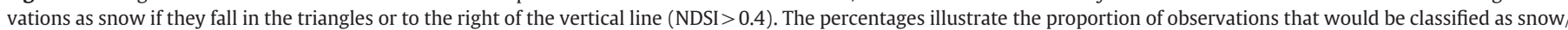
no snow in the MODIS snow mask. The functions are the linear regressions between NDVI and NDSI in snow season, along with key statistics.

in the MODIS snow products is largely due to the widely varying view angles from the MODIS instrument on a day-to-day basis. This study helps us better understand the quality of MODIS daily snow cover products, and indicates that consideration of the VZA is required in forested areas.

The modeling process showed that observations from large VZA can result in significant underestimation of VGF through forest canopies, and consequently lower the value of NDSI for winter forests. Furthermore, the MODIS gridding effects will introduce uncertainties in observations at large scan angles. When planning future satellite systems for operational snow monitoring, it should be noted that increased frequency of near nadir observations will improve results.

Empirical analysis of the MODIS products showed high day-to-day variability of the FSC for forested areas during a period with consistent snow cover. The daily averaged NDSI for a $3 \times 3$ window of snow-covered pixels at four forested sites were found to decline with increasing VZA (with some NDSI values being negative). The single center pixels of the $3 \times 3$ windows exhibited higher variability than the windows at the same site due to uncertainties introduced by the gridding process. There were strong correlations between NDSI and NDVI for four study sites. These findings support the model results, and confirm the implications of the view angle effects on viewable snow fractions. Further, they imply that it is difficult to derive snow fractions solely from NDSI for snow-covered forests, because vegetation obscures snow and considerably lowers NDSI.

This research indicates the potential for improving snow mapping in forests by explicitly taking into account the view angle effect.
Although the MODIS binary snow algorithm improved its performance in forested areas by integrating NDVI, it still has omission errors for observations at large VZA or in dense forests. In addition, the MODIS fractional snow products have trouble in estimating the FSC in forests, since NDSI is strongly view angle dependent and closely related to NDVI. It also appears that adding NDVI into consideration would help the FSC algorithm for the MODIS sensors.

A flexible way to compensate the view angle effect is to derive the function between VZA and NDSI or FSC in forested areas. This is not an easy task because that relationship is also dependent on the forest cover and the canopy structure. Dozier and Frew (2009) provided an alternative method to interpolate the estimates of the daily snow cover, thus smoothing the effects from sensor viewing geometry. The simplest solution may be to limit the use of MODIS snow data to VZA in the range of $0^{\circ}$ to $30^{\circ}$ if pixels can be identified as forests.

\section{References}

Barnes, W. L., Pagano, T. S., \& Salomonson, V. V. (1998). Prelaunch characteristics of the moderate resolution imaging spectroradiometer (MODIS) on EOS-AM1. IEEE Transactions on Geoscience and Remote Sensing, 36, 1088-1100.

Barton, J. S., Hall, D. K., \& Riggs, G. A. (2001). Remote sensing of fractional snow cover using moderate resolution imaging spectroradiometer (MODIS) data. Proceedings of the 57th Eastern Snow Conference, May 17-19, 2000, Syracuse, NY (pp. 171-183).

Dozier, J. (1989). Remote sensing of snow in visible and near infrared wavelengths. In G. Asrar (Ed.), Theory and applications of optical remote sensing (pp. 527-547). New York.

Dozier, J., \& Frew, J. (2009). Computational provenance in hydrologic science: A snow mapping example. Philosophical Transactions of the Royal Society a-Mathematical Physical and Engineering Sciences, 367, 1021-1033. 
Hall, D. K., Foster, J. L., Salomonson, V. V., Klein, A. G., \& Chien, J. Y. L. (2001). Development of a technique to assess snow-cover mapping errors from space. IEEE Transactions on Geoscience and Remote Sensing, 39, 432-438.

Hall, D. K., Riggs, G. A., \& Salomonson, V. V. (1995). Development of methods for mapping global snow cover using moderate resolution imaging spectroradiometer data. Remote Sensing of Environment, 54, 127-140.

Hall, D. K., Riggs, G. A., Salomonson, V. V., DiGirolamo, N. E., \& Bayr, K. J. (2002). MODIS snow-cover products. Remote Sensing of Environment, 83(1-2), 181-194.

Jacquemoud, S., Ustin, S. L., Verdebout, J., Schmuck, G., Andreoli, G., \& Hosgood, B. (1996). Estimating leaf biochemistry using the PROSPECT leaf optical properties model. Remote Sensing of Environment, 56, 194-202.

Klein, A. G., Hall, D. K., \& Riggs, G. A. (1998). Improving snow cover mapping in forests through the use of a canopy reflectance model. Hydrological Processes, 12, 1723-1744.

König, M., Winther, J. G., \& Isaksson, E. (2001). Measuring snow and glacier ice properties from satellite. Reviews of Geophysics, 39, 1-27.

Li, X. W., \& Strahler, A. H. (1986). Geometric-optical bidirectional reflectance modeling of a conifer forest canopy. IEEE Transactions on Geoscience and Remote Sensing, 24, 906-919.

Liu, J. C., Melloh, R. A., Woodcock, C. E., Davis, R. E., \& Ochs, E. S. (2004). The effect of viewing geometry and topography on viewable gap fractions through forest canopies. Hydrological Processes, 18, 3595-3607.

Liu, J., Melloh, R. A., Woodcock, C. E., Davis, R. E., Painter, T. H., \& McKenzie, C. (2008). Modeling the view angle dependence of gap fractions in forest canopies: implications for mapping fractional snow cover using optical remote sensing. Journal of Hydrometeorology, 9, 1005-1019.

Matson, M., Ropelewski, C. F., \& Varnadore, M. S. (1986). An atlas of satellite-derived northern hemisphere snow cover frequency. Washington, DC: National Environmental Satellite, Data, and Information Service.

Metsämäki, S. J., Anttila, S. T., Markus, H. J., \& Vepsäläinen, J. M. (2005). A feasible method for fractional snow cover mapping in boreal zone based on a reflectance model. Remote Sensing of Environment, 95, 77-95.

Ni, W. G., Li, X. W., Woodcock, C. E., Caetano, M. R., \& Strahler, A. H. (1999). An analytical hybrid GORT model for bidirectional reflectance over discontinuous plant canopies. IEEE Transactions on Geoscience and Remote Sensing, 37, 987-999.

Painter, T. H., Rittger, K., McKenzie, C., Slaughter, P., Davis, R. E., \& Dozier, J. (2009). Retrieval of subpixel snow covered area, grain size, and albedo from MODIS. Remote Sensing of Environment, 113, 868-879.
Romanov, P., Tarpley, D., Gutman, G., \& Carroll, T. (2003). Mapping and monitoring of the snow cover fraction over North America. Journal of Geophysical ResearchAtmospheres, 108.

Rosenthal, W., \& Dozier, J. (1996). Automated mapping of montane snow cover at subpixel resolution from the Landsat Thematic Mapper. Water Resources Research, 32, $115-130$.

Salomonson, V. V., \& Appel, I. (2004). Estimating fractional snow cover from MODIS using the normalized difference snow index. Remote Sensing of Environment, 89, 351-360.

Salomonson, V. V., \& Appel, I. (2006). Development of the Aqua MODIS NDSI fractional snow cover algorithm and validation results. IEEE Transactions on Geoscience and Remote Sensing, 44, 1747-1756.

Stroeve, J. C., Box, J. E., \& Haran, T. (2006). Evaluation of the MODIS (MOD10A1) daily snow albedo product over the Greenland ice sheet. Remote Sensing of Environment, $105,155-171$.

Tan, B., Woodcock, C. E., Hu, J., Zhang, P., Ozdogan, M., Huang, D., et al. (2006). The impact of gridding artifacts on the local spatial properties of MODIS data: Implications for validation, compositing, and band-to-band registration across resolutions. Remote Sensing of Environment, 105, 98-114.

Vikhamar, D., \& Solberg, R. (2003). Subpixel mapping of snow cover in forests by optical remote sensing. Remote Sensing of Environment, 84, 69-82.

Vikhamar, D., \& Solberg, R. (2003). Snow-cover mapping in forests by constrained linear spectral unmixing of MODIS data. Remote Sensing of Environment, 88, 309-323.

Warren, S. G. (1982). Optical properties of snow. Reviews of Geophysics, 20, 67-89.

Wiscombe, W. J., \& Warren, S. G. (1980). A model for the spectral albedo of snow. 1. Pure snow. Journal of the Atmospheric Sciences, 37, 2712-2733.

Wolfe, R. E., Roy, D. P., \& Vermote, E. (1998). MODIS land data storage, gridding, and compositing methodology: Level 2 grid. IEEE Transactions on Geoscience and Remote Sensing, 36, 1324-1338.

WWW1 (). http://www.wunderground.com/history/

Yang, K., \& Wolfe, R. E. (2001). MODIS level 2 grid with the ISIN map projection. Igarss 2001: Scanning the present and resolving the future. Proceedings, Vols 1-7. (pp. 3291-3293). 